the muscular tissue, which was very plainly marked. There was no thickening nor hardness around it, but the corresponding surface of the peritoneum was readily removed by the finger nail. The pyloric orifice of the stomach and the duodenum were natural, with the exception of being much bloodstained and softened. The liver was considerably smaller than natural, very hard, yellow, and hobnailed; the hepatic veins were not marked in the centre of the lobules. The gall-bladder was nearly empty.

The kidneys were natural in size, but they were much embedded in fat, and mottled on the surface. The capsule was adherent, and there were several cysts in the parenchyma, which was very granular.

The heart and lungs were healthy.

Remarks. The interest of this case consists in the enormous quantity of blood lost, and the slight morbid changes producing such loss; for though there was an ulcer, it was exceedingly superficial; and it would appear from an adhering layer of coagulum in the neighbourhood, that much must bave been lost by exudation through the coats of the vessels. From the most careful inquiries, I believe the least quantity of blood that was lost to have been two gallons; and in this belief, Mr. Roscow (who saw the case with me several times) fully coincides. Such a quantity, and continuing without intermission, would raise a suspicion that some vessel of considerable size was opened, or that there must have been an ulcerated surface of large extent; and when the previous history was taken into consideration, it appeared quite possible to have been of a malignant character. But the question of malignancy could make no difference in the treatment; for life was in momentary danger from loss of blood. The indication then clearly was, to arrest this at once if possible, and then to treat symptoms as they might arise. The most reasonable conclusion, however, that we could arrive at from the previous history was, that cirrhosis of the liver existed. Such being the case, we might have been led at first into giving too favourable a prognosis, for it is asserted that in almost all such cases hæmorrhage is merely an effort of nature to relieve the system, and that when the vessels are disgorged, the bleeding would cease of its own accord; and, later, when it was evident that something more formidable than the relief of congestion was going on, we might have lost all hope, and so have been prevented from plying remedies with sufficient perseverance. The result of this case would make it appear judicious that in all instances where life is threatened from hæmorrhage, remedies should be administered to the last, however strong our convictions that it is useless : we can never be certain.

The treatment of the case affords some points of interest: full doses of tannin frequently repeated afforded very little, if any, relief; whereas the turpentine evidently arrested it temporarily ; and it is possible that, had it been taken regularly at shorter intervals, the bleeding might have been kept in check sufficiently long to have allowed the system to recover itself, so that the patient might have eked out a few more months of miserable existence; for it was clear that when he discontinued the mixture five or six hours, blood again appeared in his vomit; not so, soon after taking his dose. The brandy, doubtless, was of much service; indeed, I believe it was that alone which kept him alive so long. In hæmorrhage occurring with cirrhosis, purgatives are recommended; in fact, are looked upon by good authorities as the only remedy; but certainly they require judicious management. In this case they were rejected by the stomach; and further, the very effort of defæcation almost extinguished the only remaining spark of life.

Fourteen days after the decease of Mr. S., one of his sons died of hæmatemesis, caused in this instance by malignant ulceration of the stomach; at least, such was the friends' version of the gentleman's report who performed the post mortem examination.

\section{CHLOROFORM, AMYLENE, ETC.: HOW DO THEY KILL?}

By Wirliam Webber, Esq., late of Norwich.

IT is not only most important, but just and right, that we should, as promptly as may be convenient, place before the public, as well as the profession, every cause of death with which we become acquairted, more especially those causes with which we have been connected, or to which we have in any way been unfortunately instrumental. This we must do without regard of any obloquy or unmerited consequences which may be visited upon us by virtue of our openness, candour, and sin431 cerity. Thus, in time, will a shortsighted, unwise, and unjust censoriousness be dispelled, and the parasitic hold of quackery will be eventually dissevered.

Where we proceed upon rational premises and sound principles, we can afford to be open. Surely, then, it is better that we should be so, than suffer ignorantly drawn inferences and consequent misrepresentation to take the initiative, and assign the office of truth to a false tongue, and to that evil genius of weakness-prejudice-the bane of progress. "Art", associated with "mystery", wears the semblance of artifice. Secresy engenders suspicion, and casts a shadow upon the fair features of science; and credulity - the cradle of empiricism-gives to imposture the benefit of the blind-born doubt.

If, in our solicitude and efforts to secure for our patients an immunity from torture (often a cause of death, from the shock it inflicts upon the conservative system of life), we accidentally destroy existence, why need we simulate the murderer's secresy, and thus, adopting a Cain-covertness, thereby convert a venial, nay, justifiable misadventure into the appearance of a felonious act? Death, under almost any circumstances, will out somehow.

To Mr. Paget and Dr. Snow, therefore, are the profession and the public indebted for having at once placed before them the correct details of the fatal results which have lately obtained to them respectively from the employment of chloroform and amylene. These hapless issues, if left to ooze out, as they unquestionably would have done, would most likely have created erroneous impressions, have done damage to the employers of the anrsthetics and to science, and have established a popular prejudice against a valuable remedy, the use of which, as a rule, is right.

It forms no part of my object here to go into the question whether chloroform, or other anesthetics of that class, have saved life by counteracting shock to the nervous system, or have enlarged the tables of mortality by their effects either at the moment of operation or in after time. I have ventured to enter upon the subject herein involved, as one anxious for the maintenance of the due status of our calling, to urge that, with life confided to our hands, a profession so eminently calculated to hold a high and honoured position, should never for an instant, through a want of moral courage and lack of openness, be subjected to the chance of its great usefulness and incalculable value being in any way evil spoken of or brought into discredit.

And now, in answer to the question, How do chloroform, amylene, or such like agents, kill? I essay, at the risk of all fair criticism (by which I may get a usefal hint, if I fail in giving one), to state that, in my humble judgment, they kill by abolishing the electric or nervous rule of the body, preventing thereby the amalgamation of those elements of the circulating fluid which are essential to function and the sustenance of life, and which no agency, independently of the nervous sovereignty, can secure. It may be asked, Why, then, do these agents kill in some instances, and not in others? Because, I apprehend (apart from an overdose, or want of due care in their administion), some depression or deterioration of nervous power, either from a fear of consequences, or the existence of organic change, or some such antecedent, has predisposed to such fatal effect. In Mr. Paget's case, the young boy "as "timid", and " became alarmed at the thought of being put to sleep". In Dr. Snuw's case, the patient, of mature age, was evidently very apprehensive of consequences, as was shown by his "not having taken food for several hours", and his "drinking a pint of ale just before the operation", and which, by generating acid, might have helped to render the chloroform more active of mischief. I consider cordials not only worse than useless, but very objectionable, in such condition of the nervous system : hence my practice of giving opiates before operations, or where I have had reason to suspect apprehension or misgivings on the part of the patient before using chloroform (as was exemplified in Baldwin's case, mentioned in my letter in the JounnaL of May 9th, under the head of "Ligature before Amputation") ; and of ordering a diet of broth or gruel, with salt and a little Cayenne pepper, for a day beforehand: hence, also, my reason for giving an opiate, with a saline stimulant, in brandy and water, after the effects of the anæesthetic have gone off, and before giving nourishment, as to me it has appeared, that to put stimulants or food into the stomach, with a view to their assimilation, when the nervous system is all but exhausted, is like expecting a spur to do more than extinguish the well nigh worn out powers of a tired horse. Allow rest and repose first to restore nervous energy, and then recruit strength by food proportionate to the power of the digestive organs. 
Again, why does the heart cease its office, and the lungs yet continue to expand and contract-aye, to inhale oxygen, but nevertheless fail to stimulate "the lord of the bosom" to persist in his wonted beat? Simply, I imagine, because the cerebral or ministerial centre has, through the agency of the "leprous distilment" poured into the blood, been deprived of the neces. sary supplies of healthy nourishment-the means, in fact, of carrying on the government and life of the constitution. The lungs, aided by the tenacious muscles, acting as long as the final contribution of nervous fluid from the spinal cord endures, afford a parallel to a bank (of "limited liability", of course), which, having disposed somehow or other of its capital, real and imaginary, deposits, and other mears, yet carries on business, with the assurance of security, till the last paid up call of the shareholders is expended, although the direction, like the paralysed heart, feels that "it is all up". The official lungs at length find their " occupation gone", and give up because they have become overpowered by the carbonic acid gas, against which, in the general ruin, they have been left hopelessly to contend. The bankrupt body then succumbs to the decomposition awaiting it, with a rapidity in propurtion to the intensity and celerity of the destroying agent, to the remaining amount of carbonic acid gas, and to the fluidity of the corrupt blood; as in cases of death from lightning, prussic acid, strychnia, etc.; or as in instances of typhus arising from the absorption of excrementitious matter, or the importation of a malarious poison, where often the decay of death begins before life ends. In Dr. Snow's case, it is much to be regretted that the condition of the brain, and also of the spleen, was not inquired into; but it occurs to me that the emphysematous state of the lungs, and the abnormal distension of the right ventricle (not detected during life), might be otherwise accounted for.

Last, but not least, comes the natural inquiry, How is threatened dissolution to be arrested where the anæsthetic, be it chloroform, amylene, or other product of that class, has turned traitor to our humane intentions? With deference, I submit, by injecting into the jugular vein distilled water impregnated with salt (the "savour" of the blood), and rousing the chords of the sleep-bound heart into harmonious play by the help of that tried and valuable adjunct, galvanism. Dr. Stevens, after despatching a rabbit by a blow upon its head, and afterwards breaking up its brain, so as to cut off entirely its connexion with the rest of the body, placed the animal upon a warm water plate, and kept up at his pleasure for many hours the heart's beat, by sprinkling upon the exposed organ salt and water: once he washed off the salt with distilled water, and its throb ceased; he renewed the saline stimulant, and it beat again : he then poisoned it with a weak solution of belladonna; it again lay motionless; again was it revived by the salt and water inspersion, and carried on its wonted contractions till the nervous supply was at an end. The experiments of Sir B. Brodie, Dr. Hope, and others, shew that the nervous centre is not essential to the heart's action, so long as a supply of nourishment is kept up.

Henceforth, then, I would recommend a Blundell's transfusion, or other properly appointed syringe; a galvanic battery ; an aromatic spirit vapour-bath, to assist in the elimination of carbonic acid gas by the skin (in preference to the negative stimulus of a chill by the dashing of cold water); a flannel dress or b] anket; flat metallic hot water bottles, with loops at the -sides or ends for tapes; a solution of salt; ammonia in sub. stance, also a saturated solution of it; bellows, a tracheal catheter, a scalpel, and a lancet,- - as the attendants in waiting upon the administration of chloroform, amylene, and the like.

Before concluding this lengthy paper, I must beg to observe, that I should be running counter to my views and feelings, were I to omit stating that to my highly gifted and much esteemed friend, Dr. Wm. Stevens (of whom my late friend, the farseeing, scientific, and amiable Dr. Prout, spoke as being "fifty years in advance of the professional knowledge of the day"), is mainly due the credit of any good which may happily arise from the suggestion I have made for the consideration of my medical brethren; which I have been led to make in consequence of my having (in the year of 1832 , during the prevalence of cholera at Great Yarmouth, where I was then practising) carried out his (Dr. Stevens's) plan by injecting salt and water into the veins of several patients who were in the last stage of choleraic collapse, by which they were recovered, after hope from all other means was gone. And I may further add, in justice to him against whom opposition, armed with all the rancour of narrowminded jealousy and the malevolent shafts of prejudice, too commonly attendant on merit, was unsparingly exercised, that I have had ample proof of the truth of another remark pronounced by Dr. Prout upon Dr. Stevens's paper on the Blood, read at the College of Physicians; namely, that his views contained "germs of discoveries of the last (English-like, I should say first) importance to mankind".

It does not appear whether galvanism was employed, or whether the means for employing it were at hand, in either $\mathrm{Mr}$. Paget's or Dr. Snow's case.

The vapour-bath is valuable in driving off sebaceous incrustations and mucoid accumulation; and it has been suggested to me by a very scientific and distinguished chemist, of whose friendship I have long enjoyed the advantage, that a vaporised ammonial solution would, by attracting the carbonic acid gas, assist in its elimination, by alternately absorbing and diffnsing or giving it off to the surrounding atmosphere.

I have been led to offer the foregoing remarks, with the special object of drawing the attention of : abler heads than mine to a subject which is creating much apprehension in the minds of the public in general, in order to prevent a fast growing discomfort from ripening into a mischievous panic.

\section{ABORTION WITHOUT HAMORRHAGE : CASE OF PROTRACTED RETENTION OF BLIGHTED OVUM.}

By R. U. West, M.D., Alford, Lincolnshire.

MrS. C. M., of S., aged 40, called me in on May 6 th, 1851. She stated that she considered herself to be about thirty-two weeks gone in the family way. Nine weeks previously, she had a sudden loss of a great quantity of "dirty-looking water"; after which, she was well again. There had been no pain and no hæmorrhage. The day before I saw her, she had begun to feel pains, which continued. There was no hæmorrhage. On instituting a vaginal examination, I found a three months (or from three to four months) foetus in the vagina. I removed it: it was a putrid mass, doubled up and compressed into a sort of oval ball, about the size of a hen's egg; it was hanging by the funis, which was very thin, and six or eight inches long. The os uteri was firmly closed, so that I made no attempt to remove the placenta. I called again two days after, and found the os uteri beginning to open; but it was still not open enough to permit the extraction of the placenta. There was no hæmorrhage, not the slightest. The placenta came away spontaneously on May 13th, there having been no hæmorrhage throughout. The woman menstruated about eleven days after the placenta came away.

In this case, most probably, the fœetus died in the thirteenth or fourteenth week of gestation. Nine or ten weeks after this event, the liquor amnii, tinged with putrescency, escaped. The foetus was still retained, notwithstanding its own death and the escape of the liquor amnii, for nine weeks longer, and the placenta yet another week, and all this without any hæmorrhage whatever.

The perusal of the case published by Dr. Roulston in the JounNaL for May 9th, has prompted me to forward for publication the above extract from my note-book.

\section{SPONTANEOUS SEPARATION OF THE LEG BY GANGRENE IN A MAN AGED EIGHTY- NINE YEARS: RECOVERY.}

By Thomas L. Pridham, Esq., J.P., Bideford, Devon.

Some weeks since, I was requested to see George Slewman, aged 89 years. I found him, considering his advanced age, looking in good health and spirits, and his intellect unimpaired. He had been a bed-lier for the last seven years. On inquiry, I heard the following extraordinary history of his case.

About a year and a half since, he complained of a pain in his heel; his wife, thinking it was rheumatism, put him on a worsted stocking. About three weeks from that time, his leg appearing to be uneasy and swollen, the stocking was removed, when a bladder was discovered extending continuously from about four inches below the knee to the end of the toes. The bladder was punctured with a needle, when a quantity of clear fluid escaped. A few days afterwards, the skin became of a brownish colour, and at the end of a week perfectly black, a distinct line of demarcation was formed. Within a few weeks, the skin became as hard as horn, and the leg had the appear432 